\title{
AGE POLYETHISM: ITS OCCURRENCE IN THE ANT \\ PHEIDOLE HORTENSIS, AND SOME GENERAL CONSIDERATIONS.
}

By Prassede Calabi', James F. A. Traniello ${ }^{1.2}$, and Michael H. WERNER ${ }^{1.2}$

\section{INTRODUCTION}

A main theme of eusociality is division of labor (Wilson 1971, 1975), which can be based on physiological differences (as in the case of the reproductive queen and sterile workers), morphological (size) differences among workers, or age differences within a physical class. In social insects both age and physical classes can comprise castes, that is, groups of individuals which perform specialized labor for sustained periods of time (physical castes: Oster and Wilson, 1978; Wilson, 1980a,b; Herbers, 1980; age castes: Oster and Wilson, 1978; Porter and Jorgenson, 1981; Mirenda and Vinson, 1981; Seeley, 1982). We constructed an ethogram for the Indo-Australian ant Pheidole hortensis, and tested the general hypothesis of division of labor in the worker caste by seeking to answer these questions:

1. Is there division of labor between physical castes?

2. Is there division of labor among age classes within a physical caste?

3. And if there is age polyethism, is it continuous or discrete? (See Wilson 1976a.)

We will consider and discuss each question separately, and then compare our results with those from other studies on social insects. In particular we will contrast age polyethism in Pheidole hortensis with that of a New World Pheidole species, P. dentata.

\section{Materials AND Methods}

\section{Data Collection}

Three colonies of Pheidole hortensis were collected in July 1979 from virgin rainforest at Gilmalé, Sri Lanka by Anula Jayasuriya.

\footnotetext{
'Department of Biology, Boston University, Boston, MA 02215

2Museum of Comparative Zoology Laboratories, Harvard University. Cambridge. MA 02138

Manuscript received hy the editor August 8, 1983
} 
The ants were identified by E. O. Wilson, and voucher specimens deposited in the collection at the Harvard Museum of Comparative Zoology. Colonies thrived and produced brood in artificial nests made of glass tubing of $5 \mathrm{~mm}$ diameter (approximately that of twigs in which wild colonies have been found (Jayasuriya 1979), and fitted with moist cotton plugs. Colonies were maintained at $26^{\circ} \mathrm{C}$ while observations and experiments were carried out.

As is typical of this genus, $P$. hortensis has a completely dimorphic worker caste. And, as is true for many ant species in general, newly eclosed $P$. hortensis are quite light in color, and darken as they age. Using the method first described by Wilson (1976a), we found that based on these color differences and the degree of pigmentation of body parts each physical caste could reliably be separated into five color or age classes (see Appendix I). Using the obvious size and color differences, ethogram data on workers of different ages was compiled from 24 hours of observation on one colony over a ten week period.

The nest tube and surrounding area were watched, and every observed act was noted along with the age class and physical caste of the ant performing it. During the 24 hours of observation 3,689 acts of 25 behaviors were recorded for minor workers, and 256 acts of six behaviors for majors. At the end of the study the colony consisted of 192 minors, 32 majors, brood, and the queen.

\section{Data Analysis}

Completeness of the behavioral repertory was assessed by statistical comparison with a lognormal Poisson distribution (Bulmer 1974, Fagen and Goldman 1977).

The hypothesis of age-based division of labor was tested with a standard $\chi^{2}$ comparison between observed performance frequencies by each age class for behaviors, and expected frequencies generated with the following formula (Altmann and Altmann 1977):

$$
E_{i j}=\frac{\left(B_{i}\right)\left(n_{j}\right)}{N}
$$

$E_{i j}=$ Expected frequency of Behavior $_{i}$ by age class $j_{j}$

$B_{i}=$ Observed frequency of Behavior $r_{i}$ by all age classes

$n_{j}=$ Number of ants in age class $j_{j}$

$\mathrm{N}=$ Total number of ants in all age classes combined 
We excluded from analysis behaviors with frequencies $<1 \%$ of all behaviors performed by that physical caste; for $P$. hortensis that gives a possible frequency per behavior of about 25 , or five occurrences per age class, under the null hypothesis.

Associations between age class and behavior were assessed by a relative performance measure (RPM). We calculated the probability that ants of a particular age class will perform a given behavior, and divided those ratios by the highest such probability for that behavior. Thus

$x=$ frequency of behavior $_{i}$ performance by ants of age class ${ }_{j}$,

$\mathrm{y}=$ frequency of all behaviors by age class $\mathrm{j}_{\mathrm{j}}$,

$\mathrm{z}=$ highest such frequency for that behavior ${ }_{\mathrm{i}}$, and $\mathrm{RPM}=(\mathrm{x} \div \mathrm{y})$ $\div \mathrm{z}$.

Finally, any attempt at an ergonomic assessment requires that one distinguish between task and non-task behaviors. We use the terms as follows. "Behavior" means a logical unit like grooming, made up of one or more physical acts, such as drawing the tibial comb over the antennae. "Task" is used in the sense of Oster and Wilson (1978) to denote a set of acts which achieve some purpose of the colony. Thus there are task and non-task behaviors, and though all tasks are behaviors, not all behaviors are tasks.

\section{RESULTS}

\section{Completeness of Repertory.}

The repertory of each physical caste separately and of the species as a whole was judged complete, based on statistical comparison with a lognormal Poisson distribution (Bulmer 1974, Fagen and Goldman 1977). For minors, the observed repertory size is 25 behaviors, and the estimated size is 26 , with a $95 \%$ confidence interval of [23, 29]. For majors, six behaviors were observed, and six estimated, with a $95 \%$ confidence interval of $[5,7]$. For $P$. hortensis the observed repertory includes 31 behaviors, with 33 estimated, and a $95 \%$ confidence interval of $[30,36]$.

\section{Division of labor by physical castes.}

Comparison of the behavioral repertories of the two physical castes shows that there is, with the exception of trophallaxis, no overlap in task performance (Table 1). Of the tasks carried out, 
brood care, food acquisition, and allogrooming are performed by minors and defensive tasks by majors. Defense by minors was seen only when the colony was experimentally submitted to attack by other ant species, and even then the two physical castes performed different tasks: minors pinioned foreign ants, making it easier for majors to snip them up.

\begin{tabular}{|c|c|c|}
\hline & MINOR & MAJOR \\
\hline Selfgroom & $789(.21)$ & $110(.43)$ \\
\hline Allogroom Minor & $136(.04)$ & 0 \\
\hline Allogroom Major & $70(.02)$ & 0 \\
\hline Allogroom Queen & $9(.002)$ & 0 \\
\hline Carry Egg & $307(.08)$ & 0 \\
\hline Carry Larva & $1235(.33)$ & 0 \\
\hline Carry Pupa & $149(.04)$ & 0 \\
\hline Groom Egg & $24(.01)$ & 0 \\
\hline Groom Larva & $223(.06)$ & 0 \\
\hline Groom Pupa & $225(.06)$ & 0 \\
\hline Assist Larval Eclosion & $114(.03)$ & 0 \\
\hline Assist Pupal Eclosion & $6(.001)$ & 0 \\
\hline Trophallaxis w/Larva & $25(.01)$ & 0 \\
\hline Trophallaxis w/Minor & $48(.01)$ & $8(.03)$ \\
\hline Trophallaxis w/Major & $5(.001)$ & 0 \\
\hline Trophallaxis w/Queen & $2(.001)$ & 0 \\
\hline Retrieve Food & $186(.05)$ & 0 \\
\hline Forage & $22(.01)$ & 0 \\
\hline Eat Brood/Exuvia & $37(.01)$ & 0 \\
\hline Eat Dead Adult & $26(.01)$ & 0 \\
\hline Carry Brood/Exuvia & $46(.01)$ & 0 \\
\hline Carry Dead Adult & $7(.001)$ & 0 \\
\hline Carry Meconium & $1-$ & 0 \\
\hline Carry Nest Material & $1-$ & 0 \\
\hline Eat Solid Food in Nest & $4(.001)$ & 0 \\
\hline Patrol at Food & 0 & $52(.20)$ \\
\hline Patrol Arena & 0 & $22(.08)$ \\
\hline Guard & 0 & $63(.25)$ \\
\hline Totals & $3685(1.00)$ & $255(1.00)$ \\
\hline
\end{tabular}

Table I. Ethogram of Pheidole hortensis. Observed frequencies are followed by values in parentheses indicating the frequency of each act relative to the total number of behaviors performed by a physical caste. 
Both castes exchange food with minors, but trophallaxis is relatively more important in the majors' repertory. Though its actual frequency is low, it constitutes their only non-defense task, and it comprises $5 \%$ of the tasks they perform versus only $1 \%$ for minors. In fact, when all categories of trophallaxis by minors are combined (with majors, larvae, and the queen as well as with minors), trophallaxis still comprises only $2 \%$ of the minors' task repertory. This relative frequency of the behavior by majors led us to ask whether majors serve as a replete or "cask" caste, as in Camponotus fraxinicola (Wilson 1974). Pheidole hortensis majors with full gasters show a three-fold weight increase, but we were unable to perform the critical experiments and test for proportionate weight gain. However, in random surveys of the colony, replete majors (those with distended gasters) performed virtually none of the behaviors typcial of majors (Table 2). During experimentally induced attack (assault with sympatric Tetramorium spp.), replete majors engaged in defense only if the attack was severe (many ants) or extended in time. How much of this inactivity by "storage" majors is due to protecting the food supply and how much to relative inability to move is not clear.

Another potential set of caste differences relates to the granivorous habits of many Pheidole species in which minors harvest and majors mill seeds. In an attempt to observe such caste differences in $P$. hortensis, we offered grass, vegetable, and bird seeds of various sizes and fat contents. All were ignored by both physical castes.

3. Division of labor by age classes within a physical caste.

To answer this question, we tested the null hypothesis that each age class should perform a given behavior in proportion to the number of ants in that age class. Thus, in a colony with three age

Patrol at Food

Patrol Arena

Guard Nest Entrance
Attack Intruder

$\begin{array}{cc}\text { "Replete" Majors } & \text { Non-"Repletes" } \\ 12 & 66 \\ 0 & 8 \\ 1 & 18 \\ 0 & 20\end{array}$

Tahle 2. Behavioral differences within the major worker caste of Pheidole hortensis. The numbers of individuals observed performing various acts during random surveys of the colony are presented. 
classes comprising 30,20 , and $50 \%$ of the total colony, there is no age polyethism if those age classes perform 30, 20, and 50\% respectively of any task. The data show that the age classes of both physical castes do not perform tasks in proportion to their numbers (Table 3). On the basis of $\chi^{2}$ comparisons, for most tasks with adequate sample sizes the null hypothesis can be rejected because there are significant differences between the observed and expected frequencies. This indicates that there is age-based division of labor in both physical castes (Table 4). Four tasks by minors (assist ecolsion, allogroom majors, trophallaxis with minors, and carry exuviae) are performed without apparent age bias, and eight behaviors by minors and one by majors were observed too rarely to permit assessment.

Thus of behaviors with an adequate sample size, for $P$. hortensis minors 13 of 17 , and for majors four or five, behaviors show agebased division of labor.

\section{Continuous versus discrete age castes.}

Wilson (1976a) states that division of labor is discretized if there is an exclusive association between (sets of) tasks and age class(es) and that it is continuous under all other conditions of age class/task association. The general question of age polyethism has two parts. Given that some tasks are performed more or less often by certain age classes, can adjacent age classes be combined because they show similar performance patterns? And second, are such associations between age class(es) and tasks exclusive? To test for associations, we calculated relative performance measures (RPM) for each age class by behavior. This descriptive way of treating the data controls for variation in age class size and in number of performances observed per age class, and it permits comparison between frequently and rarely occurring behaviors, as well as comparisons of age class performances within and between behaviors.

Figure 1 shows that there are no consistent similarities between the relative performance probabilities for any pairs of adjacent age classes. This implies that no pair of age classes can be combined, and that these age classes do differ behaviorally, representing real castes. It is also clear that the associations between age castes and tasks or groups of tasks are not exclusive: the age-based division of labor is continuous rather than discretized in both the minor and 


\begin{tabular}{|c|c|c|c|c|c|c|}
\hline $\begin{array}{l}\text { MINOR WORKERS } \\
\text { AGE CLASS }\end{array}$ & $\mathrm{I}(15)$ & $\mathrm{II}(27)$ & III(45) & IV(24) & $\mathrm{V}(81)$ & $\begin{array}{r}\text { ROW } \\
\text { OTAL } \\
192\end{array}$ \\
\hline Selfgroom & 78 & 159 & 221 & 95 & 228 & 781 \\
\hline Allogroom Minor & 10 & 5 & 38 & 22 & 61 & 136 \\
\hline Allogroom Major & 5 & 7 & 25 & 11 & 22 & 70 \\
\hline Carry Egg & 11 & 121 & 77 & 30 & 68 & 307 \\
\hline Carry Larva & 20 & 93 & 470 & 159 & 493 & 1235 \\
\hline Carry Pupa & 1 & 18 & 42 & 24 & 64 & 149 \\
\hline Groom Egg & 5 & 7 & 6 & 3 & 3 & 24 \\
\hline Groom Larva & 8 & 28 & 94 & 38 & 55 & 223 \\
\hline Groom Pupa & 8 & 57 & 65 & 23 & 72 & 225 \\
\hline Assist Eclosion & 10 & 26 & 23 & 14 & 41 & 114 \\
\hline Trophallaxis w/ Larva & 1 & 1 & 15 & 2 & 6 & 25 \\
\hline Trophallaxis $\mathbf{w} /$ Minor & 1 & 7 & 19 & 6 & 15 & 48 \\
\hline Forage & 0 & 0 & 0 & 2 & 20 & 22 \\
\hline Retrieve Food & 0 & 2 & 24 & 39 & 121 & 186 \\
\hline Eat Brood/Exuvia & 0 & 2 & 22 & 3 & 10 & 37 \\
\hline Eat Dead Adult & 0 & 1 & 14 & 2 & 9 & 26 \\
\hline Carry Exuvia & 0 & 6 & 13 & 4 & 23 & 46 \\
\hline COLUMN TOTAL & 158 & 540 & 1168 & 472 & 1311 & 3654 \\
\hline \multicolumn{7}{|l|}{ MAJOR WORKERS } \\
\hline AGE CLASS & $\mathrm{I}(5)$ & $\mathrm{II}(15)$ & $\operatorname{III}(5)$ & $\operatorname{IV}(3)$ & $V(4)$ & 32 \\
\hline Selfgroom & 13 & 58 & 30 & 8 & 1 & 110 \\
\hline Guard & 3 & 4 & 14 & 20 & 22 & 63 \\
\hline Patrol at Food & 0 & 0 & 2 & 3 & 47 & 52 \\
\hline Patrol Arena & 0 & 0 & 0 & 1 & 21 & 22 \\
\hline COLUMN TOTAL & 16 & 62 & 46 & 32 & 91 & 247 \\
\hline
\end{tabular}

Tahle 3. Observed frequencies with which each age class ( $\mathrm{I}$ through $\mathrm{V}$ ) performed various acts. Values in parentheses indicate the number of individuals in each age class. 


\begin{tabular}{lrrr}
\multicolumn{1}{c}{ MINORS } & N & X & P \\
Selfgroom & 781 & 65.9 & $* *$ \\
Allogroom Minor & 136 & 13.4 & .01 \\
Allogroom Major & 70 & 7.8 & NS \\
Carry Egg & 307 & 178.7 & $* *$ \\
Carry Larva & 1235 & 212.3 & $* *$ \\
Carry Pupa & 149 & 13.1 & .02 \\
Groom Egg & 24 & 14.1 & .01 \\
Groom Larva & 223 & 58.6 & $* *$ \\
Groom Pupa & 225 & 34.8 & $*$ \\
Assist Eclosion & 114 & 7.9 & NS \\
& & & .001 \\
Trophallaxis w/Larva & 25 & 18.8 & NS \\
Trophallaxis w/Minor & 48 & 8.7 & $* *$ \\
& & & $* *$ \\
Forage & 186 & 79.3 & $* *$ \\
Retrieve Food & 22 & 22.5 & .01 \\
& & & NS \\
Eat Brood/Exuvia & 37 & 27.9 & \\
Eat Dead Adult & 26 & 15.0 & \\
Carry Exuvia & 47 & 5.2 &
\end{tabular}

\section{MAJORS}

Selfgroom

Guard

Patrol at Food

Patrol Arena
110

63

52

22
23.7

13.3

290.1

138.8

Tahle 4. $\mathrm{X}^{2}$ values and significance levels for differences between observed and expected behavior frequencies for the five age classes within each physical caste. ** indicates that the $\mathbf{P}$ values were so small they do not appear in the $X^{2}$ table and are highly significant. NS, no significant difference. Only behaviors with frequencies $\geqslant$ $1 \%$ are included. $\mathrm{N}=$ total number of acts observed. 
A

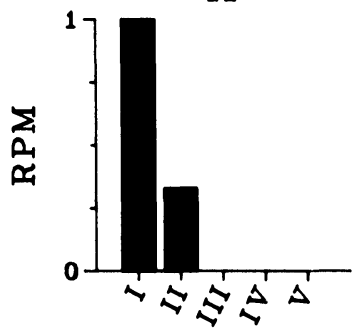

B

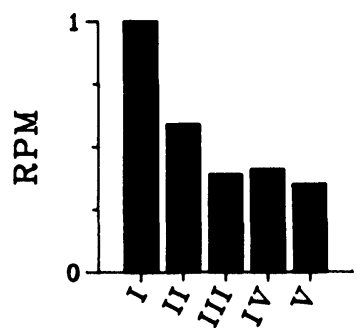

C

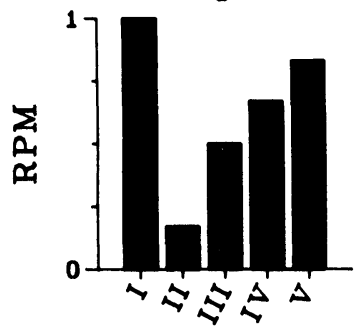

D

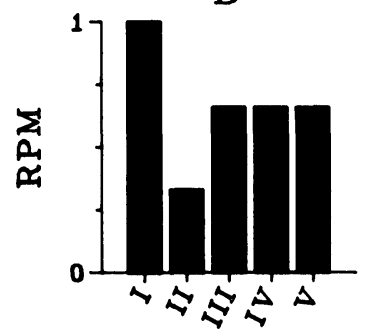

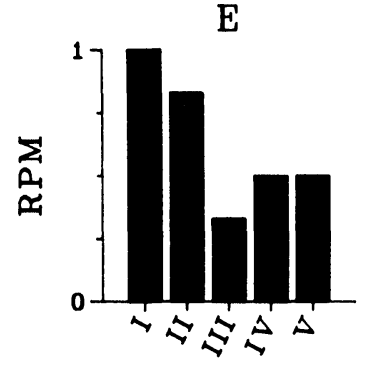
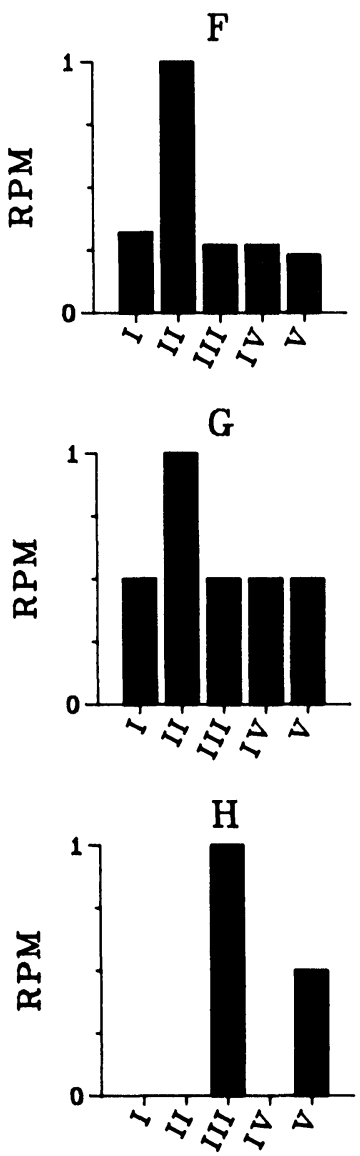

Figure 1. Relative performance measures (RPM) of various behaviors in the repertories of major (MJI-MJ4) and minor (A-Q) workers of Pheidole hortensis. Roman numerals I-V correspond to worker age classes. Additional details in Materials and Methods. 

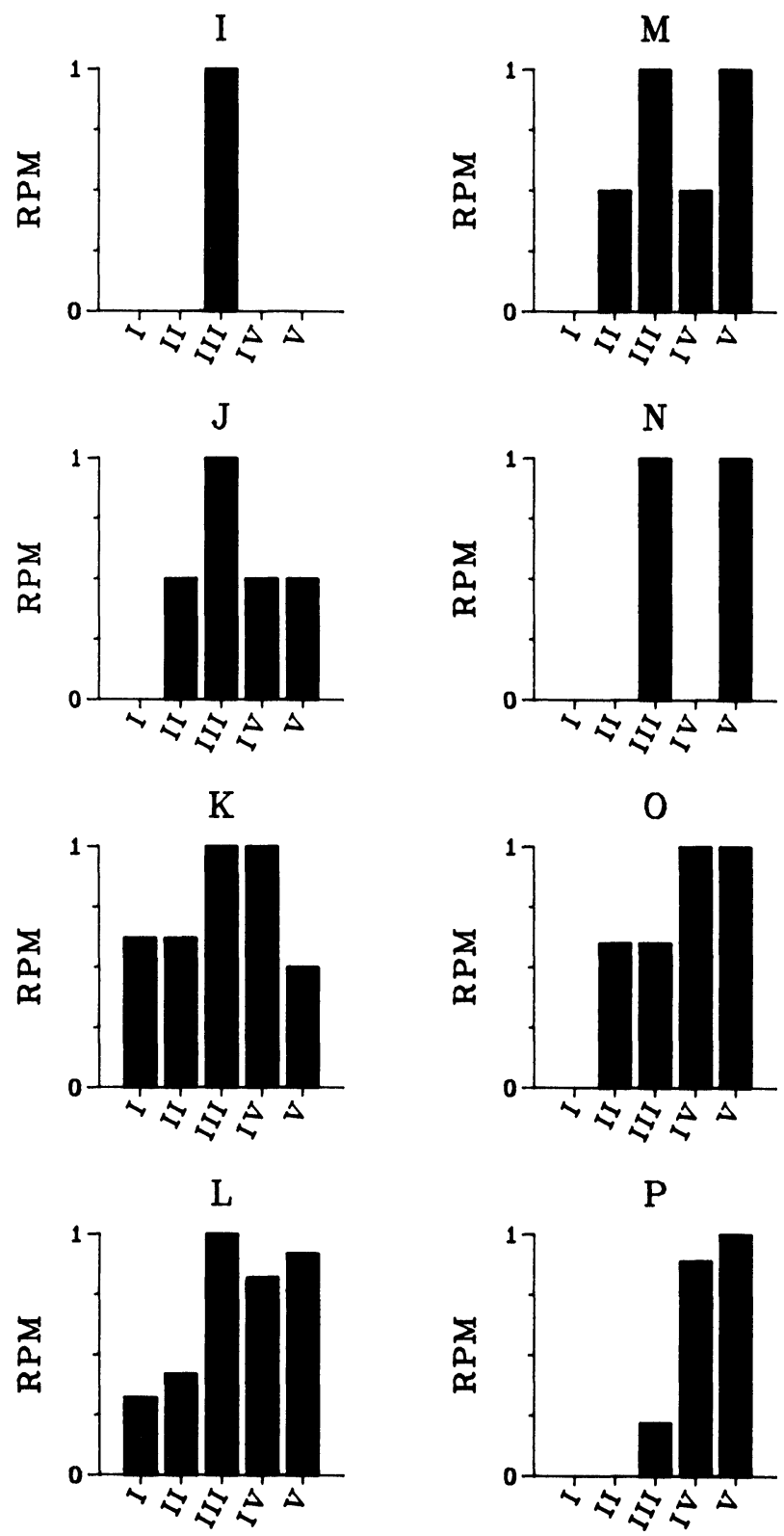

Figure 1. (Continued) 

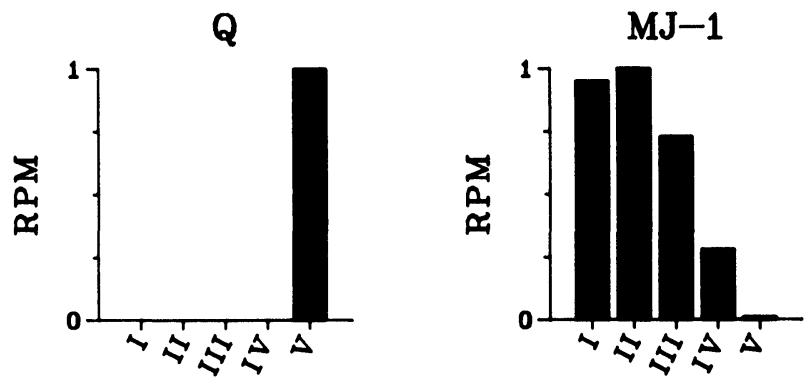

MINORS

A Groom Egg

B Selfgroom

C Allogr. Minor

D Allogr. Major

E Assist Eclosion

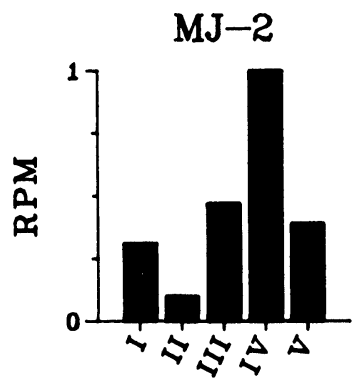

F Carry Egg

G Groom Pupa

MJ-3

$\mathrm{H}$ Eat Brood/Skin

I Troph w/ Larva

$\mathrm{J}$ Troph w/ Minor

K Groom Larva

L Carry Larva

M Carry Brd/Skin

$N$ Eat Dead Adult

O Carry Pupa

$P$ Retrieve Food

Q Forage

MAJORS

MJ-1 Selfgroom

$\mathrm{MJ}-2$ Guard

MJ-3 Patro1 @ Food

MJ-4 Patrol Arena
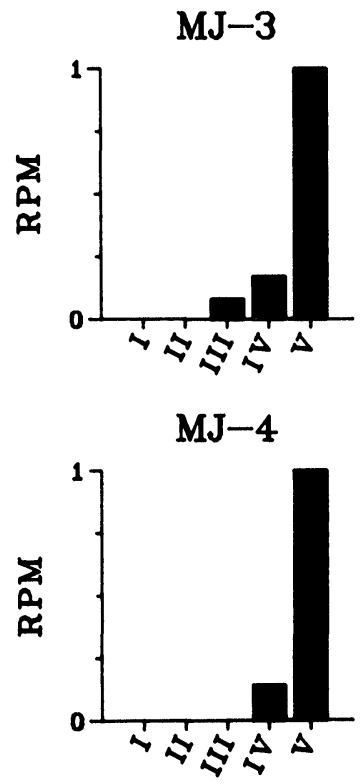

Figure 1. (Continued) 
major physical castes. For instance, in Figure 1 examine the minors' behaviors $\mathrm{F}, \mathrm{G}$, and $\mathrm{E}$, and the series $\mathrm{H}$ through $\mathrm{N}$. The relative performance measures for tasks $\mathrm{F}$ and $\mathrm{G}$ are highest for age class II, yet age classes II and I have similarly high R PM for task E. Or, in the second case, for all the tasks $\mathrm{H}$ through $\mathrm{N}$, age class III shows very high RPM, but the task/age class association is not exclusive. For $\mathrm{K}, \mathrm{M}$, and $\mathrm{N}$ at least, other, but not necessarily adjacent age classes, show similarly high R PM.

\section{Discussion}

$P$. hortensis exhibits both physical and age castes, and the latter show continuous rather than discretized polyethism. We will compare these results with results from other species, and consider some of their general implications for the study of age polyethism.

\section{Repertory size and numerical considerations.}

Both repertory size and the proportion of rarely occurring behaviors in P. hortensis are in the same range as those of other species. Numbers of behaviors in repertories judged complete by Fagen and Goldman analysis are: 27 for workers of monomorphic Leptothorax species (Wilson and Fagen 1974) and for minor workers of Orectognathus versicolor (Carlin 1982), and 28 each for minor Pheidole dentata (Wilson 1976a), Formica perpilosa (Brandão 1979), and Camponotus sericeiventris (Busher 1982). Extremes may be represented by minor repertories of Solenopsis geminata, $S$. invicta, and Zacryptocerus varians: 17, 20, and 38, respectively (Wilson, 1976b, 1978). Repertories for majors range from two (Solenopsis geminata, Wilson 1978) to 24 (Orectognathus versicolor, Carlin 1982); for the dimorphic Z. varians and P. dentata, major repertories are 11 and nine (Wilson 1976a and b). Total repertories for all these species range from 20 to 40 behaviors.

Given the similarity in repertory size for minor workers of both $P$. hortensis and $P$. dentata, it may seem odd that in $P$. hortensis considerably fewer behaviors ( 13 vs 23 ) are performed with age bias. The difference results from the respective criteria used to reject rarely occurring behaviors from analysis. Because he does not make statistical comparisons, Wilson rejects only 2 of 28 behaviors on grounds of insufficient data. However, when the cut-off criterion 
used for $P$. hortensis is applied (rejected behaviors with frequencies $<1 \%$ of those performed by that physical caste) the number of behaviors rejected for $P$. dentata increases from two to seven of 28 $(\mathrm{N}=1,222$; Wilson 1976a). Thus the appropriate comparison of agebiased behaviors among behaviors with frequencies $\geqslant 1 \%$ shows a similar situation for the two: 13 of 17 behaviors for P. hortensis, and 15 of 19 for P. dentata. Of behaviors performed without apparent age bias, allogroom majors and trophallaxis with majors, are in common to the two species. (In general ant repertories include high proportions of infrequent behaviors: for minors 10 of 28 ( $P$. dentata -Wilson 1976a), 27 of 38 (Zacryptocerus varians -Wilson 1976b) 7 of 28 (Formica perpilosa-Brandão 1979), 14 of 27 (Orectognathus versicolor-Carlin 1982) and 9 of 28 (Camponotus sericeiventrisBusher 1982). Although some castes have small repertories (majors of P. dentata and Solenopsis geminata,-Wilson 1976a, 1978), many other castes show similar proportions of infrequent to frequent behaviors (Wilson and Fagen 1974, Traniello 1978, Brandão 1979, Carlin 1982).

\section{Age-based division of labor.}

It is a virtual truism that among social insects older workers forage and have little or nothing to do with brood care. Yet in $P$. hortensis older workers, in addition to performing all foraging and food retrieval ( $\mathrm{P}$ and $\mathrm{Q}$, Figure 1), show high R PM for several brood-care tasks ( $\mathrm{K}, \mathrm{L}, \mathrm{M}$, and $\mathrm{O})$. We suggest that these represent labor cohorts, based on ant experience or colony need. They could arise via the mechanism of task fixation, a feedback-based task stabilizing mechanism documented in wasps (Forsyth 1978) and suggested for the ant Amblyopone pallipes (Traniello 1978). An individual performs some task (e.g., trophallaxis with larvae), receives positive feedback (continually finds hungry larvae), and over time does not switch to other tasks because the positive feedback does not cease. The susceptibility of individuals to task fixation could vary so that even in a system with age-based taskswitching, task fixation might override age-based behavioral change.

Although it remains to be demonstrated whether such fixation occurs in $P$. hortensis, we wish to point out one possible consequence of task fixation and the resultant caste "atypical" be- 
havior. A colony labor profile by age class could be an artifact of previous colony needs and activities, specifically for the period previous to the study by just less than an average worker life span. For instance, suppose that a colony engaged in high brood production several weeks previous to observations. There would have been both need and opportunity for much brood care, and also opportunity for fixation on brood tasks. Further imagine that the food supply then dwindled and brood production decreased. Some older workers are fixated on and keep performing brood care tasks, leaving little need for younger workers to perform this task, and therefore little opportunity for task fixation. At the time of observation, RPM for brood care would show older castes performing proportionately more brood care. Yet it may be misleading and actually incorrect to draw the conclusion that older castes "typically" perform brood care. R PM are epiphenomena of past (and current) colony labor needs, and may say less about age castes as such than about behavioral flexibility and colony requirements. Therefore, appropriate conclusions must consider this, and include at least a time frame, plus consideration of colony age, size, and circumstance.

\section{Continuous versus discrete castes; roles}

By definition, discretization of age castes is a direct consequence of roles (a group of tasks) linked by high transition probabilities, and exclusively or principally performed by a particular age caste (Oster and Wilson 1978, Wilson 1976a). Our results for P. hortensis show a continuous mode and, therefore, no roles. This differs from results of other age polyethism studies. Wilson (1976a) and Seeley (1982) find behavioral discretization by age, and roles. Both also argue that spatial efficiency is its basis, with each role (suite of tasks) involving a set of physically proximate contingencies. If that is the case, differences among the species and especially between $P$. hortensis and $P$. dentata, could account for the results. Colony size in $P$. hortensis is a few hundred, in comparison with up to a thousand in P. dentata. The former nests in twigs or small nuts, the latter in logs often with underground galleries. Thus for $P$. hortensis, spatial efficiency may be an irrelevant consideration.

However, other more basic considerations may also be involved. Mirenda and Vinson (1981) elaborate on Wilson's (1976a) use of 
"caste" and "subcaste." Because the two treat their data differently, comparisons are difficult, but we suggest that the castes and subcastes of Mirenda and Vinson correspond to the discrete and continuous modes of Wilson. Mirenda and Vinson consider as subcastes "(a) groups of individuals within each caste whose behaviour is statistically but not completely differentiated from other such groups and (b) groups intermediate in behaviour between two or more castes, but not completely distinct from any caste" (1981, p. 417). Both descriptions, and especially the latter, seem to fit the criteria for a continuous caste system-overlap in frequency distribution of age classes performing various tasks-rather than the discrete system, characterized by an exclusive association between an age class and a group of tasks. If this correspondence is indeed correct, we may be that much closer to a functional understanding of labor roles, spatial efficiency, caste, and how task performance of individual ants sum to performance of whole castes. It is also noteworthy that although Mirenda and Vinson do not address the question of spatial efficiency as such, their results show a strong correspondence between ant age, location, and "career," their "role" analogue.

Clearly there is age-based division of labor in Pheidole hortensis. It does not seem to follow traditional role patterns, nor is it obvious which pattern it does follow. Therefore, we suggest two factors which must be considered for $P$. hortensis in particular, and in studies of age polyethism in general: "atypical" behavior due to labor cohorts, and role performance. Both have been documented for physical castes (Oster and Wilson 1978); one for age castes (Oster and Wilson 1978, Mirenda and Vinson 1981, herein). Because of these specializations, we suggest that mean behavioral performances by age classes may not be sufficiently fine-grained for detailed ergonomic analysis, and that the study of behavioral specialization and its ergonomic consequences requires bouts of continuous observation of individually marked animals throughout their lives.

\section{SUMMARY}

We present evidence for and describe age-based division of labor in the Indo-Australian ant Pheidole hortensis. Both the minor and major physical castes exhibit age polyethism, and in both castes age 
polyethism is continuous rather than discretized. There is virtually no overlap between the sets of tasks performed by the two physical castes. These findings differ in several respects from those reported in two other studies of age polyethism (in the New World $P$. dentata and in Apis mellifera), and raise some interesting questions about labor roles in social insects.

\section{ACKNOWLEDGEMENTS}

Thanks to L. Calabi for invaluable discussion of, and help with, data analyses; to T. D. Seeley for a preprint of his paper and enlightening discussion of his methods; to S. D. Porter for a critical reading; to D. S. Gladstein for technical assistance with estimating repertory completeness; and to $\mathrm{W}$. $\mathrm{R}$. Tschinkel for pointing out an important reference.

\section{REFERENCES}

Altmann, S. A. and J. Altmann

1977. On the analysis of rates of behavior. Anim. Behav. 25: 364-372. Brandão, C. D.

1979. Division of labor within the worker caste of Formica perpilosa Wheeler. (Hymenoptera:Formicidae). Psyche 85: 229-237.

BI'LMER, M. G.

1974. On fitting the Poisson lognormal distribution to species-abundance data. Biometrics 30: 101-110.

BI'SHER, C.

1982. Polymorphism and division of labor in Camponotus sericeiventris. Honors Thesis, B.A., Boston University.

CARIIN. N. F.

1982. Polymorphism and division of labor in the Dacetine ant Orectognathus versicolor (Hymenoptera:Formicidae). Psyche 88: 231-244.

FAGin, R. M. AND R. N. GoldDMAN

1977. Behavioural catalogue analysis methods. Anim. Behav. 25: 261-274.

Forsyth, A. B.

1978. Behavioral Ecology of Polygynous Social Wasps. Ph.D. Thesis, Harvard University.

Herbers, J. M.

1980. On caste ratios in ant colonies: population responses to changing environments. Evol. 34(3): 575-583.

JAYASURIA, A. K.

1980. The behavior and ecology of Aneuretus simoni Emery. Honors Thesis, B.A. Harvard University 
Mirfida, J. T. and S. B. Vinson.

1981. Division of labor and specification of castes in the red imported fire ant Solenopsis invicta Buren. Anim. Behav. 29: 410-420.

Oster, G. F. And E. O. Wilson.

1978. Caste and Ecolog! in the Social Insects. Princeton University Press, Princeton, N.J.

Portir, S. D. and C. D. Jorgensen.

1981. Foragers of the harvester ant, Pogonomyrmex onyheei: a disposable caste? Behav. Ecol. Sociobiol. 9: 247-256.

SFrify, T. D.

1982. Adaptive significance of the age polyethism schedule in honeybee colonies. Behav. Ecol. Sociobiol. 11: 287-293.

Traniei.i.o, J. F. A.

1978. Caste in a primitive ant: absence of age polyethism in Amblyopone. Science 202: 770-772.

WIISON, E. O.

1971. The Insect Societies. Belknap Press of Harvard University Cambridge, MA.

1974. The soldier ant Camponotus (Colobopsis) fraxinicola as a trophic caste. Psyche 81: 182-188.

1975. Sociobiolog!: The New Sinthesis. Belknap Press of Harvard University.

1976a. Behavioral discretization and the number of castes in an ant species. Behav. Ecol. Sociobiol. 1: 141-154

1976b. A social ethogram of the neotropical arboreal ant Zacryptocerus varians (Fr. Smith). Anim. Behav. 24: 354-363

1978. Division of labor in fire ants based on physical castes (Hymenoptera: Formicidae:Solenopsis). J. Kansas Entom. Soc. 51: 615-636

1980a. Caste and division of labor in leaf-cutter ants (Hymenoptera:Formicidae:Atta). I. The overall pattern in A. sexdens. Behav. Ecol. Sociobiol. 7: $143-156$.

1980b. Caste and division of labor in leaf-cutter ants (Hymenoptera:Formicidae:Atta). II. The ergonomic optimization of leaf cutting. Behav. Ecol. Sociobiol. 7: 157-165.

WIISON, E. O. AND R. M. FAgEN.

1974. On the estimation of total behavioral repertories in ants. N.Y. Entomol. Soc. 82: 106-112.

\section{Appendix I}

Hue and degree of pigmentation for the color (age) classes of the two physical castes of $P$. hortensis.

\section{MinORS.}

Class I-White-yellow: head and thorax, pale white/light grey; gaster, light grey; petiole and femur, pale white/light yellow; tibia, grey. 
Class II-light yellow: head and thorax, light yellow with amber outlines, especially dark amber edging the mandibles; gaster, medium grey; petiole, dark yellow with amber outlines; femur, light yellow/brown; tibia, grey.

Class III-yellow-grey: head and thorax, dark yellow, head with grey in occipital region; gaster, dark grey; petiole, yellow; femur, dark yellow/brown; tibia, grey.

Class IV-amber: head and even mandibles, solid amber; thorax, amber with some brown; gaster, dark grey/black; petiole, amber with brown outlines; femur, brown; tibia, grey.

Class $V$-amber-grey: head, dark amber with brown streaks through occipital region; thorax, solid amber; gaster, black/dark grey; petiole, amber/brown; femur, brown; tibia, grey.

MAJORS

Class 1-white-yellow: head, pale white; thorax and petiole, pale white/light yellow; gaster, light grey.

Class II-yellow: head and thorax, yellow; petiole, light brown/amber.

Class III-amber: head, dark amber; thorax, dark yellow; gaster, dark grey; petiole, light brown/amber.

Class IV-medium brown: head, dark brown with lighter tinges; thorax, amber; gaster, dark grey; petiole, dark brown.

Class $V$-dark brown: head and gaster, dark, dark brown/black; thorax and petiole, dark brown. 

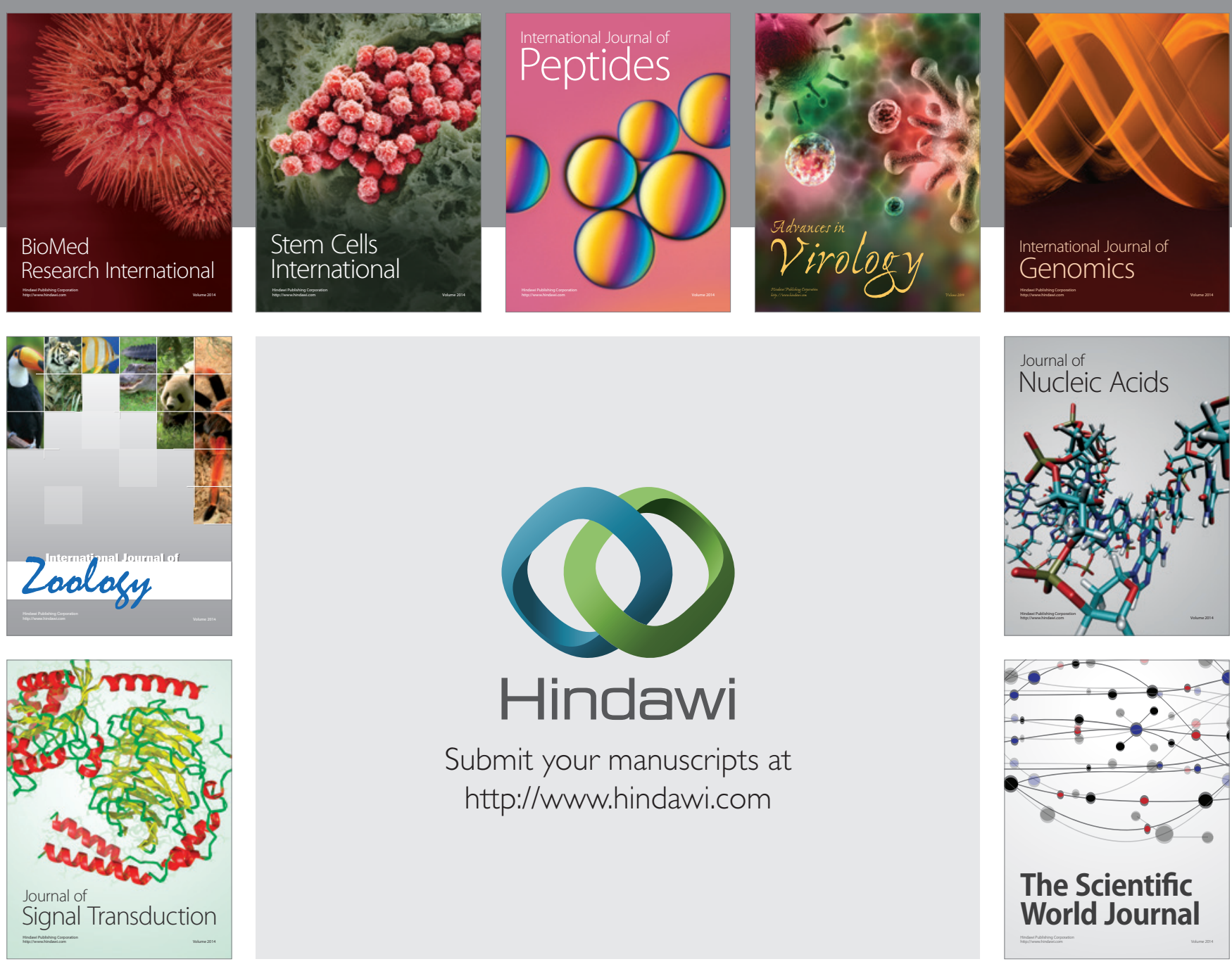

Submit your manuscripts at

http://www.hindawi.com
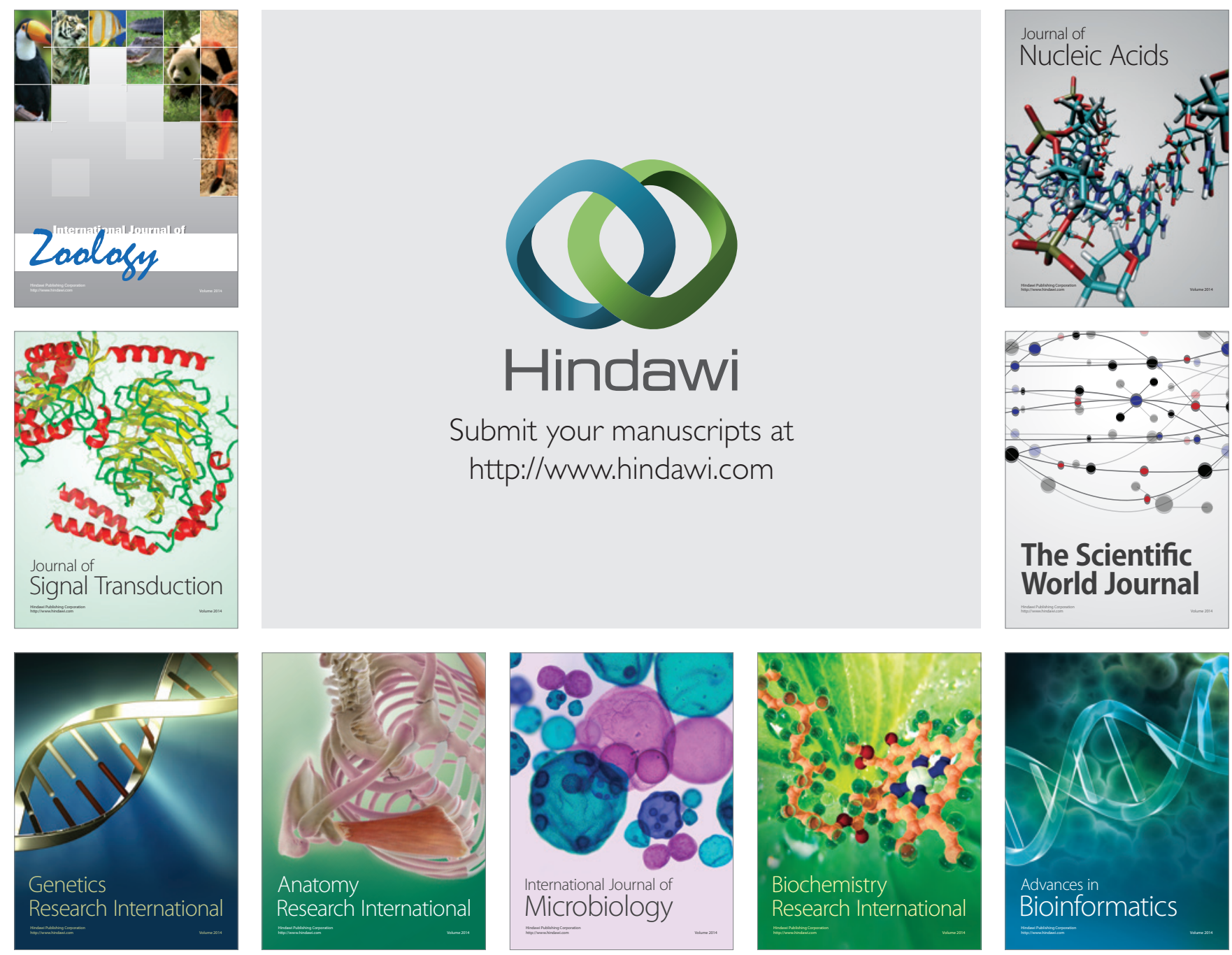

The Scientific World Journal
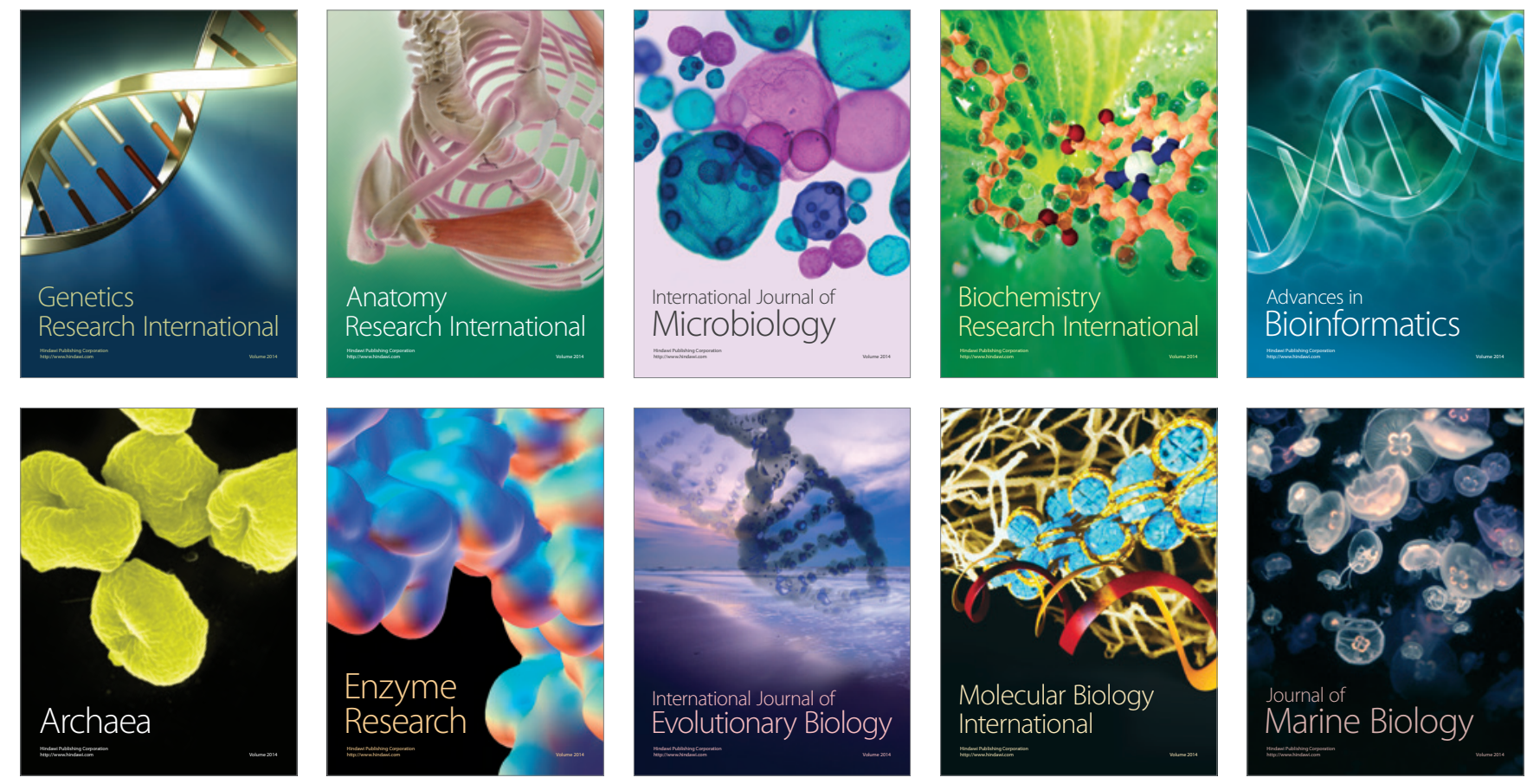